\title{
ANÁLISE DA INFLUÊNCIA DO PÉ-DIREITO NA DISPONIBILIDADE DE ILUMINAÇÃO NATURAL NO AMBIENTE INTERNO
}

\author{
Adriana Baccari Farkas ${ }^{1}$ \\ Andréa Coelho Laranja ${ }^{2}$
}

DOI: 10.5752/P.2316-1752.2018v25n37p189

\begin{abstract}
Resumo
A iluminação natural depende de parâmetros externos e internos ao ambiente, dentre eles a própria geometria interna do espaço. Este artigo verifica a influência do pé-direito na disponibilidade de iluminação natural no ambiente interno, utilizando como metodologia a simulação no software Troplux. Conclui-se que o parâmetro pé-direito $2.6 \mathrm{~m}$ é adequado à distribuição de iluminação natural se comparado aos pés-direitos mais elevados. Em relação à uniformidade, as análises revelaram que, à medida que há o aumento do pé-direito, eleva-se a uniformidade, todavia nenhum dos resultados de uniformidade satisfez a NBR 8995-1.
\end{abstract}

1. Graduada em Design de Interiores e Pós-Graduada "lato sensu" em Design de Interiores pelas Faculdades Integradas Espírito-Santenses (FAESA). E-mail: adrianabaccari@ yahoo.com

2. Doutora em Arquitetura e Urbanismoe e Professora Adjunta do Departamento de Arquitetura e Urbanismo na Universidade Federal do Espírito Santo (UFES). E-mail: andreacoelholaranja@gmail.com 
Palavras-chave: Iluminação natural. Pé-direito. Conforto ambiental. 


\section{ANALYSIS OFTHE INFLUENCE OFTHE CEILING HEIGHT ON THE AVAILABILITY OF NATURAL} LIGHTING INTHE INTERNAL ENVIRONMENT

\begin{abstract}
The daylight depends on external parameters and internal to the environment, among them the inner geometry of the space itself. This study verifies the influence of the ceiling height in the availability of natural lighting in the internal environment. Using as simulation methodology the software Troplux. It is concluded that, the parameter height $2.6 \mathrm{~m}$ is suitable for the distribution of daylight, when compared to the higher ceiling height. In relation the uniformity while there is the increase of the ceiling height there is an elevation of the uniformity, however none of the reached results of uniformity satisfied the NBR 8995-1.
\end{abstract}

Keywords: Daylight. Ceiling height. Environmental confort.

\section{ANALISIS DE LA INFLUENCIA DEL PIE-DERE- CHO EN LA DISPONIBILIDAD DE ILUMINACIÓN NATURAL EN EL MÉDIO AMBIENTE INTERNO}

\section{Resumen}

La iluminación natural es dependiente de parámetros, externos e internos al ambiente, entre ellos la propia geometría del espacio interno. Este artículo verifica la influencia del Pie-derecho en la disponibilidad de iluminación natural en el ambiente interno. La metodología sutilizó simulaciones en software Troplux. Conclusión, el parámetro Pié-derecho (PD) $2,6 m$ es favorable a la distribución de la iluminación en el ambiente. Las análisis revelan también que a medida que hay el aumento del pie-derecho hay una elevación de la uniformidad, pero ninguno de los resultados de uniformidad alcanzados satisface la NBR 8995-1.

Palabras-claves: Iluminación natural. Pie-derecho. Confort térmico. 


\section{Introdução}

O Brasil tem à sua disposição grande oferta de incidência de iluminação natural durante o ano. Essa iluminação natural, ao ser utilizada com critério, permite o desempenho lumínico dos ambientes, contribuindo na redução do gasto com energia elétrica para iluminação artificial, bem como traz benefícios físicos e psicológicos aos seus usuários. Desse modo, Assaf e Pereira (2003), Oral et AL (2004) e Laranja (2010) alertam que, para que se alcance o conforto visual do usuário no ambiente interno, há a necessidade não só de uma adequada distribuição de luminosidade e do controle do ofuscamento, mas também de níveis adequados de iluminância, em função das atividades humanas a serem realizadas nos ambientes.

Diante disso, observam-se inúmeras pesquisas que buscam compreender o comportamento da iluminação natural no ambiente interno, a partir da variação de parâmetros externos e internos em relação à edificação. No que diz respeito aos parâmetros externos, citam-se Laranja (2010), Nunes (2011) e Monteiro (2013, apud Santos ET al,2015), os quais apontam, dentre os parâmetros externos, a verticalização e o adensamento urbano crescente das cidades, na medida em que há perda de quantidade e de qualidade da iluminação natural no espaço urbano e, por consequência, no ambiente interno. 
Em relação aos parâmetros internos, consideram-se os estudos de Hopkinson et al (1975), Li et al (2006), Cabús $(2002,2007)$ e Laranja et al $(2014,2016)$, em que se aponta a dependência da iluminação no ambiente interno das refletâncias das superfícies internas, da geometria do ambiente interno como a altura (pé-direito), largura e profundidade do ambiente interno, bem como da disposição, orientação e tamanho das aberturas.

Sob essa ótica, em função das questões citadas anteriormente, tornam-se pertinentes estudos investigativos mais refinados sobre os parâmetros influenciadores da iluminação natural no ambiente interno. Dessa forma, a presente pesquisa tem como objetivo verificar a influência do pé-direito na disponibilidade dessa iluminação natural.

A partir dos resultados, observando o comportamento da distribuição da luz natural no ambiente interno, de acordo a modificação do parâmetro pé-direito (PD), será possível auxiliar nas decisões projetuais dos profissionais da área, bem como na organização normativa da escala da edificação - Código de Obras - e da escala do urbano - Plano Diretor Urbano -, com vistas a promover a potencialização da iluminação natural no ambiente interno. 


\section{Metodologia de trabalho}

Como instrumento para as simulações, foi adotado o programa computacional Troplux 7.3.2 (CABUS, 2006), um dos programas de simulação da iluminação natural sugeridos pelo RTQR (REGULAMENTO TÉCNICO DA QUALIDADE PARA O NÍVEL DE EFICIÊNCIA ENERGÉTICA EDIFICAÇÕES RESIDENCIAIS), disponível em BRASIL (2010). O Troplux apresenta-se como software que permite a simulação das características da iluminação natural em ambiente interno, sendo possível configurar o céu da localidade (CABUS, 2006). O recorte territorial adotado localiza-se na cidade de Vitória/ES-Brasil, Latitude 20¹9'S. Adotou-se a altura de $45 \mathrm{~m}$ para as edificações obstruídoras do entorno, que corresponde a uma edificação de quatorze andares, prática comumente encontrada no cenário urbano estudado (Figura 1). 


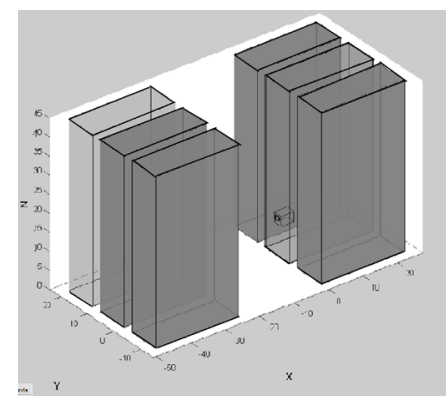

Figura 1| Perspectiva sem escala do Troplux - Cenário urbano da simulação.

Fonte: Autora

Sobre a via perpendicular à abertura considerada, priorizou-se o valor de 18m (rua + passeio) no dimensionamento da largura, em referência à tipologia para via "Local Principal", de acordo com o Plano Diretor Urbano de Vitória (VITÓRIA, 2006).

Adotou-se como referência o trabalho desenvolvido por Nikiforiadis e Pitts (2003) e Araújo e Cabús (2007) citado por LARANJA et al (2014), para as características de reflexão das superfícies externas adotadas. Desse modo, foram adotados 0,6 para superfícies externas verticais (edificações obstruidoras) e horizontais (vias), e para piso adotou-se 0,2 . 


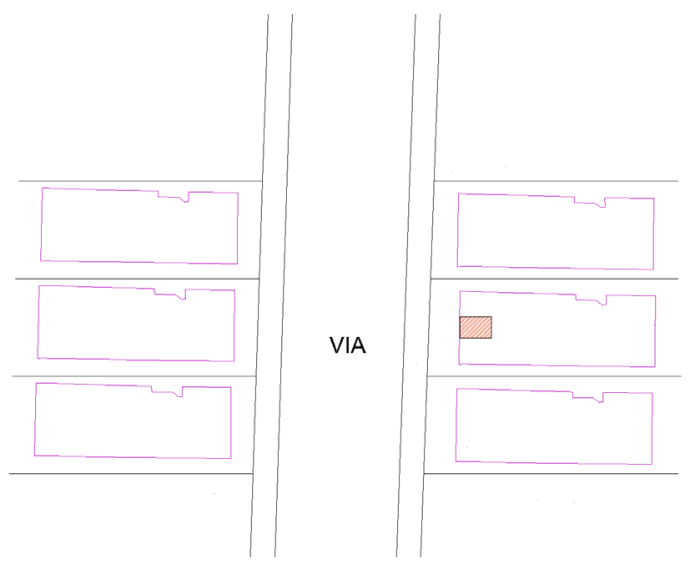

Figura 2 | Vista Superior do cenário urbano, edificações obstruidoras e via, com destaque para o ambiente interno simulado.

Foram utilizadas nas simulações três tipos de céus padrões da CIE (Commission InternationaleL'aclairage - 2003): Céu tipo 3 (encoberto), Céu tipo 7 (parcialmente nublado) e tipo 12 (claro), de acordo com Laranja (2010), cujos estudos realizados, para valores da média anual de iluminância interna bem como percentuais das UDIs, definem esses tipos de céus como os que correspondem respectivamente aos valores mínimo, intermediário e máximo de iluminância no ambiente interno, respectivamente. 


\section{Características do Ambiente Interno Adotado}

Este estudo teve como base um modelo de ambiente de uma edificação residencial multipavimentos, de acordo o critério de dimensões mínimas para o ambiente - área, largura e pé-direito - exigidos pelo Código de Obras de Vitória-ES (VITORIA 1998). Esse modelo de ambiente interno, podendo ser quarto ou sala, foi simulado no quarto andar de um edifício, em cenário urbano da cidade de Vitória, considerando que os usos dos pavimentos inferiores são normalmente destinados para lazer e garagem. Assim, o ambiente interno caracteriza-se por possuir o pé-direito de 2,60m, largura de 2,60m e comprimento de $3,85 \mathrm{~m}$. Em sequência, sendo mantidas as características da largura e comprimento do ambiente, foram feitas simulações tendo sido adotados novos pés-direitos para as simulações: $3.10 \mathrm{~m}, 3.60 \mathrm{~m}, 4.10 \mathrm{~m}$ e, por último, 4,60m para o mesmo ambiente.

As refletâncias internas adotadas foram: 0,8 para teto, 0,2 para piso e 0,6 para parede. O modelo possui abertura centralizada na parede, composta de vidro liso transparente, com área de abertura de $1,25 \mathrm{~m} 2$, largura de $1,14 \mathrm{~m}$ e altura de $1,10 \mathrm{~m}$, correspondente à proporção de $1 / 8$ da área do piso do compartimento de acordo com o estipulado no Código de Obras de Vitória (VITÓRIA, 1998). A orientação das aberturas foi simulada no cenário urbano, considerando a 
fachada com a abertura perpendicular ao traçado urbano. Nas simulações foram testadas as aberturas orientadas para norte, sul, leste e oeste.

\section{Pontos de medição no Ambiente Interno}

Como forma de observar o decaimento da iluminância, optou-se por adotar sete pontos de avaliação ao longo do cenário, a uma distância, entre eles, de $50 \mathrm{~cm}$, localizados ortogonalmente à abertura e a uma altura de $75 \mathrm{~cm}$ do piso, de acordo com a ABNT - NBR 15215-4 (BRASIL, 2005). Dessa forma, o ponto 1, o mais próximo da abertura, e os pontos subsequentes distanciando-se a cada $0,5 \mathrm{~m}$ entre si. Observam-se, na Figura 03, os sete pontos de medição distribuídos no ambiente e localizados da seguinte forma em relação à sua profundidade: PT $1=0,5 \mathrm{~m} ; \mathrm{PT} 2=1,0 \mathrm{~m}$; PT $3=1,5 \mathrm{~m} ;$ PT $4=2,0 \mathrm{~m}$; PT $5=2,5 \mathrm{~m}$; PT $6=3,0 \mathrm{~m}$; e PT $7=3,5 \mathrm{~m}$ esquema. 

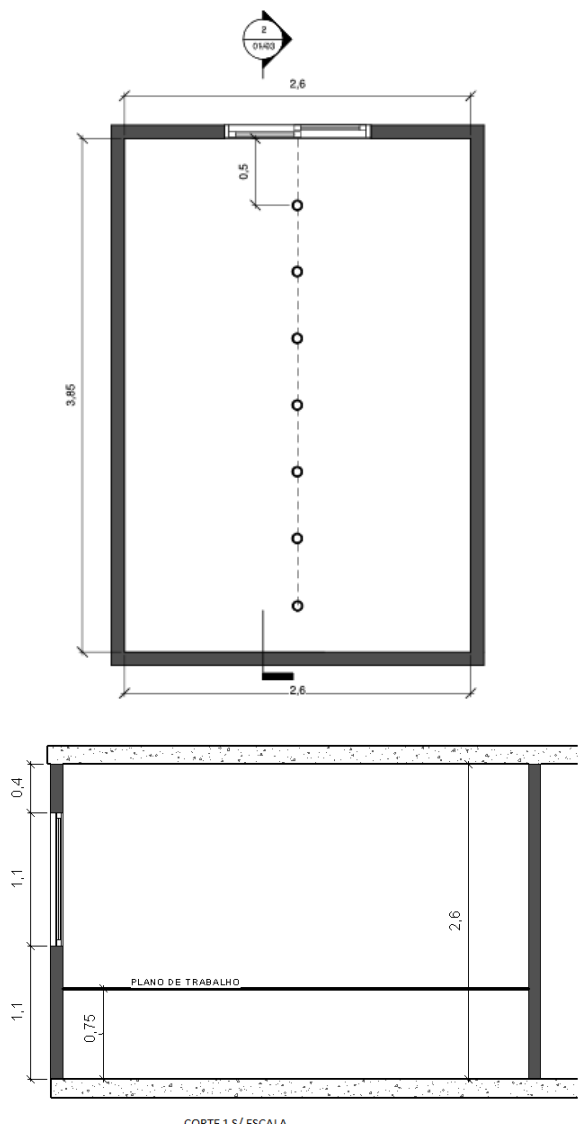

Figura 03 | À esquerda, Planta Baixa sem escala, com pontos de medição da lluminância. À direita, Corte1 com PD 2.6m com marcação dos pontos de medição da iluminância na altura do plano de trabalho.

Fonte: Autora 


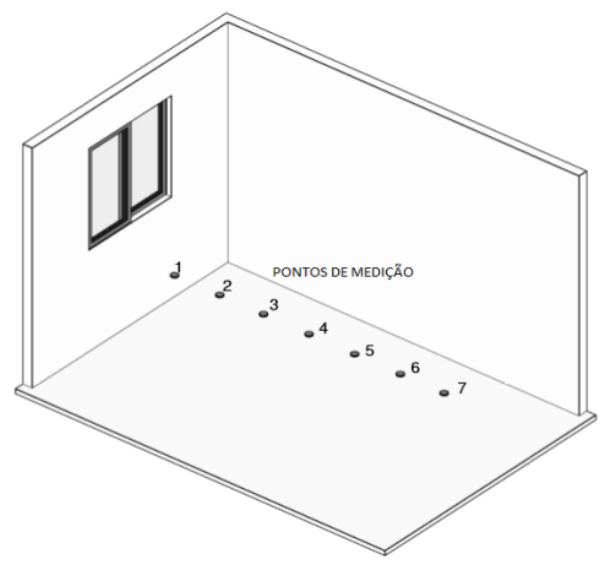

Figura 4 | Perspectiva do Ambiente interno com pontos de medição da iluminância.

Na simulação, foram obtidos os valores das iluminâncias que foram comparados aos percentuais de valores dos intervalos das UDI (Useful Daylight Iluminance), propostos por Nabil e Mardaljevic (2006), sendo eles:

a) $E<100$ : faixa de intervalo insuficiente (inapropriados);

b) $100 \leq E<500$ Ix: faixa de intervalo suficiente, mas que necessita de iluminação complementar;

c) $500 \leq E<2000 \mathrm{Ix}$ : faixa de intervalo suficiente;

d) E >2000: são valores excessivos (inapropriados);

Os valores de iluminância média e os percentuais das UDIs foram obtidos em função das simulações para todos os 
dias do ano nos horários compreendidos entre $8 \mathrm{~h}$ e $17 \mathrm{~h}$. Em relação a U (Uniformidade), utilizaram-se os valores das iluminâncias obtidas em datas e em horários específicos: solstícios e equinócios - respectivamente em 21 de março e 21 de dezembro, nos horários de 8h, 10h, 14h e 16h. A uniformidade foi obtida por meio da razão entre a iluminância mínima e a iluminância média, conforme orienta a NBR 8995-1. Adotaram-se os seguintes valores de Uniformidade: $U>7$; para entorno imediato $U>0,5$; para área de trabalho $U>0,6$.

As análises permitiram verificar:

e) O decaimento da iluminância no ambiente interno, por intermédio da curva isolux, durante o Equinócio (21 de março) e o Solstício (21 de dezembro) nos horários de 8h, 10h, 14h, 16h, para a orientação sul.

f) Os valores da iluminância média global de todos os dias do ano em horários compreendidos entre 8h e 17h;

g) Os percentuais de distribuição dos intervalos das UDls no ambiente interno em função de todos os dias do ano nos horários compreendidos entre $8 \mathrm{~h}$ e 17h;

h) A uniformidade da iluminação em função de sua distribuição no ambiente durante o Equinócio (21 de março) e o Solstício (21 de dezembro) nos horários de 8h,10h,14h,16h. 


\section{Resultados}

De acordo a metodologia estabelecida, a partir da extração dos dados, foram elaborados gráficos e tabelas no MS Excel, considerando o ambiente com aberturas orientadas para norte, sul, leste e oeste.

\section{Análise dos Percentuais de lluminância interna para Céu 3 (encoberto)}

Para o Céu 3 (encoberto), o gráfico 01 apresenta o percentual anual da iluminância interna do ambiente, dentro dos intervalos percentuais das faixas UDI em todas as orientações de fachada. Observa-se que, para todas as orientações simuladas, a variação do pé-direito (PD) não demonstrou alteração nos percentuais de horas da UDI, em que, independente do pé-direito adotado, somente cerca de $14 \%$ das horas do ano se encontram no intervalo $500 \leq E<2000$ lx (suficiente). Por conseguinte, demonstra-se, para todos os pés-direitos, uma grande demanda por iluminação artificial. 


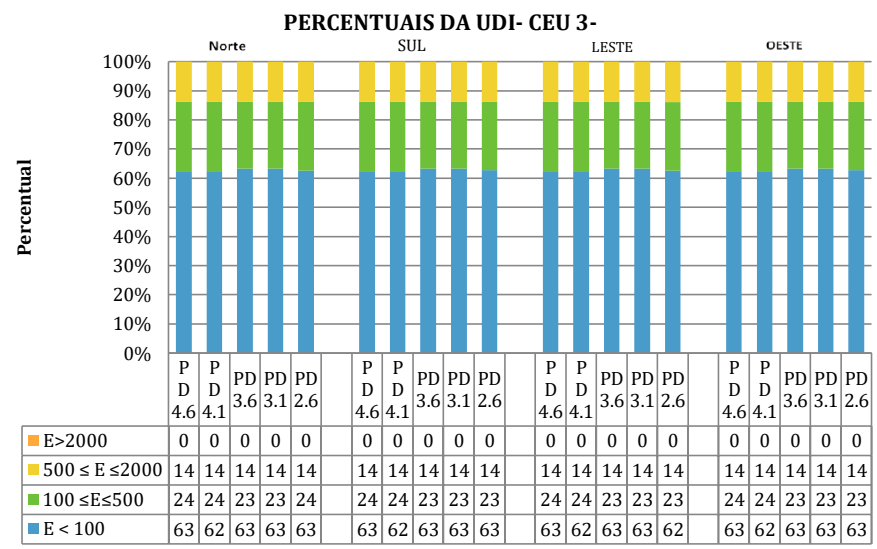

Gráfico 1 | Comparativo entre percentual das UDIs durante o ano de acordo orientação da fachada.

Fonte: Autora

\section{Análise da lluminância Média nos Solstícios e Equinó- cios para Céu 3 (encoberto)}

Para o Céu 3 (encoberto), o Gráfico 02 revela que, nas curvas Isolux, como já era esperado, para todos os pés-direitos, em todos os horários simulados, os pontos mais próximos da abertura apresentam um valor de iluminância superior aos demais pontos.

Nota-se, entretanto, que independente da orientação da abertura a iluminância próxima da abertura é sempre mais 
evidente, em todos os horários, para o pé-direito mais baixo. Reconhece-se o seu pico nos horários das $10 \mathrm{~h}$ e 14h, mais evidente no Solstício de Verão (21 de março e 21 de dezembro), acarretando, consequentemente, um maior desconforto visual nesses horários, em função do elevado contraste luminoso no ambiente interno.

Por fim, observa-se que essa iluminância (no ponto 1) decresce à medida que são aumentados os pés-direitos. Nota-se, porém, que o aumento do pé-direito apenas contribui para a redução da iluminância nos pontos mais próximos da abertura sem, porém, reduzir demasiadamente a iluminância nos pontos mais distantes da abertura. Dessa forma, haverá uma redução dos contrastes lumínicos no ambiente interno para ambientes com maiores pés-direitos, melhorando consequentemente o conforto visual do ambiente interno.

Conclui-se, portanto, uma redução na amplitude de variação da iluminação no ambiente interno à medida que se aumenta o pé-direito. Como consequência, aponta-se para uma redução dos contrastes lumínicos no ambiente interno, contribuindo para o conforto visual. 


\section{ILUMINÂNCIA EM 21 DE MARÇO E 21 DE DEZEMBRO - CÉU 3 - N,S,L,L,0}

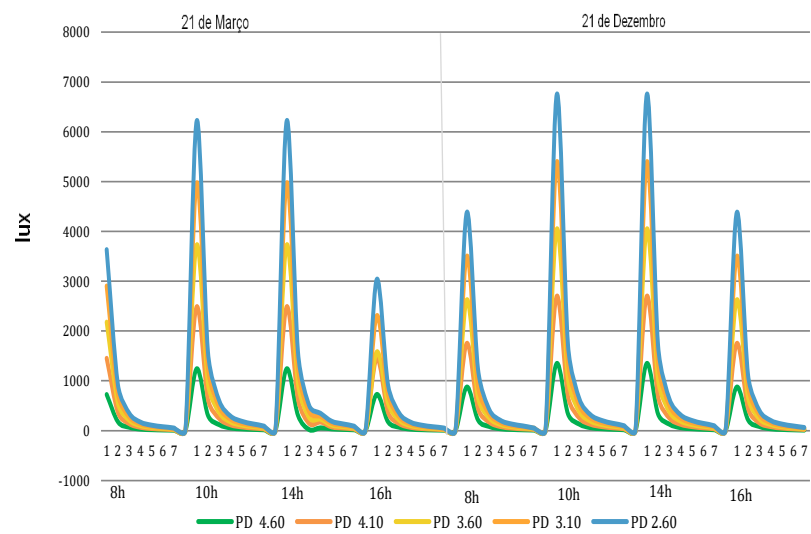

Gráfico 2 | Distribuição da lluminância no Equinócio e Solstício para Céu 3 (encoberto) Orientação N, S, L e O.

Fonte: Autora

\section{Análise dos Percentuais de Iluminância interna para Céu 7 (parcialmente nublado)}

Percebe-se nos Gráficos 03 e 04 que, para Céu 7 (parcialmente nublado), para todas as orientações simuladas, a variação do parâmetro pé-direito (PD) não demonstrou alteração nos percentuais de horas da UDI. Isto é, independente do pé-direito adotado, somente valores entre $14 \%$ e $22 \%$ se encontram no intervalo $500 \leq \mathrm{E}<2000 \mathrm{~lx}$ (suficiente), sendo os menores valores para abertura orientada para norte e os maiores para sul. Os resultados acima indicam, para to- 
dos os pés-direitos, uma elevada demanda por iluminação artificial no ambiente interno.

PERCENTUAIS DA UDI- CEU 7-

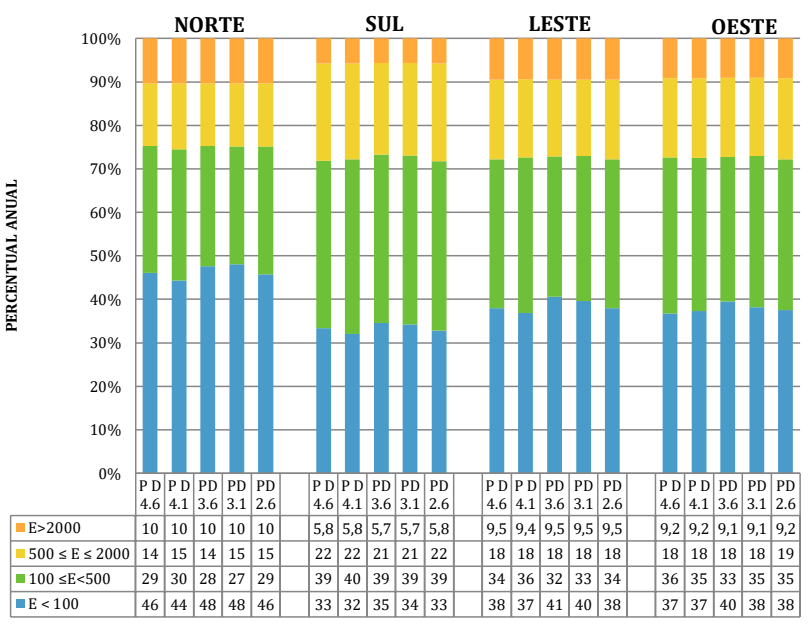

Gráfico 3 | Comparativo entre percentual das UDIs em Céu 7 durante o ano de acordo orientação da fachada.

Fonte: Autora.

Para o Céu 7 (parcialmente nublado), o Gráfico 04 revela que, nas curvas Isolux, como já era esperado, para todos os pés-direitos, os pontos mais próximos da abertura apresentam um valor de iluminância superior aos demais pontos. Observa-se, porém, que essa iluminância próxima da abertura é sempre mais evidente, em todos os horários, para o pé-direito mais baixo. O seu pico persiste nos horários das $10 \mathrm{~h}$ e 14h, mais evidente no Solstício de Verão (21 de 
dezembro), em orientação sul, provavelmente em função do acesso da radiação solar direta nesse ambiente. Tal fato acarretará, para essa orientação sul, consequentemente, um maior desconforto visual nesses horários, havendo necessidade de inserção de dispositivos sombreadores para controlar os excessos da iluminação. A iluminância (no ponto 1) em questão decresce à medida que são aumentados os pés-direitos, sendo isso mais evidente nos horários em que a altura solar é maior, $10 \mathrm{~h}$ e $14 \mathrm{~h}$, provavelmente em função do maior acesso da radiação solar em função da maior altura dos ângulos solares. Assim, pode-se apontar a necessidade de incorporação de dispositivos sombreadores em ambientes com pés-direitos mais baixos, de forma a reduzir à alta iluminância nos pontos próximos da abertura, reduzindo o contraste visual e contribuindo para o conforto lumínico.

Conclui-se, dessa forma, a redução na amplitude da iluminação no ambiente interno com o aumento o pé-direito. Logo, aponta-se uma redução nos contrastes de iluminação e um conforto lumínico no ambiente interno. 


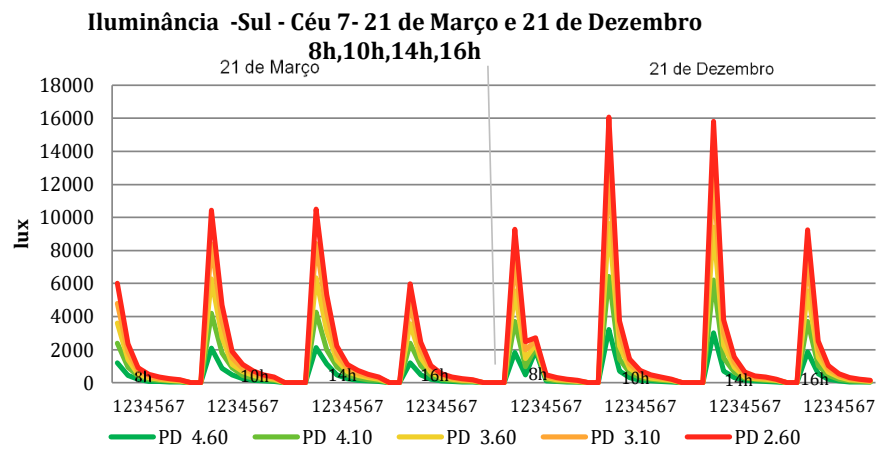

Gráfico 04 | Distribuição da lluminância pelos pontos de coleta no Equinócio e no Solstício para Céu 07 - Orientação SUL

Fonte: Autora

\section{Análises dos Percentuais de iluminância interna para Céu 12 (claro)}

Nota-se que no Gráfico 05, o Céu 12 (claro), para todas as orientações simuladas, a variação do parâmetro Pé-direito (PD) não demonstrou alteração nos percentuais de horas da UDI. Isto é, independente do pé-direito adotado, somente valores entre $23 \%$ e $34 \%$ se encontram no intervalo $500 \leq \mathrm{E}<2000 \mathrm{~lx}$ (suficiente), sendo os menores valores provenientes da orientação norte e os maiores valores provenientes da orientação sul. À vista disso, percebe-se, para todos os pés-direitos, uma alta demanda por iluminação artificial. 


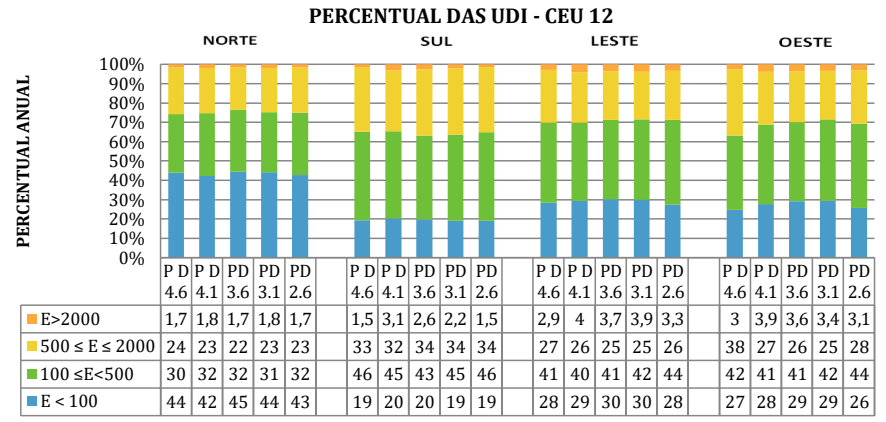

Gráfico 05 | Comparativo entre percentual das UDIs durante o ano de acordo orientação da fachada

Fonte: Autora

Para o Céu 12 (claro), o Gráfico 06 revela que, nas curvas Isolux, como já era esperado, para todos os pés-direitos, em todos os horários simulados, os pontos mais próximos da abertura apresentam um valor de iluminância superior aos demais pontos.

Observa-se, porém, que essa iluminância próxima da abertura é sempre mais evidente, em todos os horários, para o pé-Direito mais baixo. Isto é, o seu pico persiste nos horários das $10 \mathrm{~h}$ e $14 \mathrm{~h}$, mais evidente no Solstício de Verão em (21 de março), em orientação sul. Em suma, tal fato acarretará, consequentemente, em um maior desconforto visual nesses horários. Assim, a iluminância (no ponto 1) 
em questão decresce à medida que são aumentados os pés-direitos.

Conclui-se, dessa forma, uma redução na amplitude de variação da iluminação no ambiente interno à medida que se aumenta o pé-direito. Esse resultado aponta, portanto, para uma redução nos contrastes de iluminação no ambiente interno.

\section{Iluminância -Sul - Céu 12- 21 de Março e 21 de Dezembro} 8h,10h,14h,16h

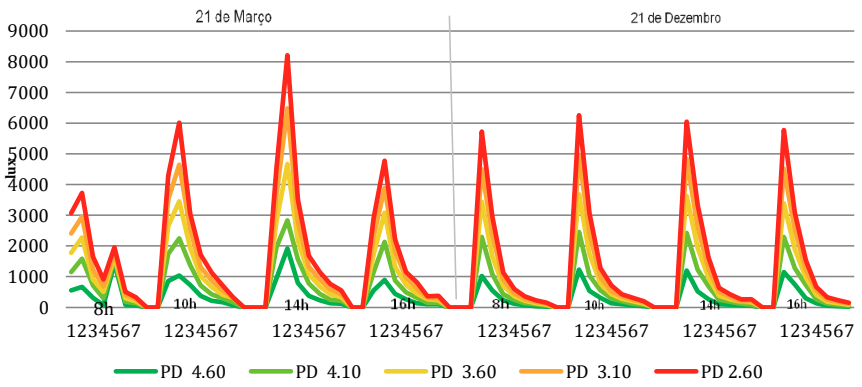

Gráfico 06 | Distribuição da lluminância pelos pontos no ambiente e horário de coleta no Equinócio e no Solstício para Céu 12 (claro) - Orientação SUL

Fonte: Autora 
Nos gráficos 07 e 08 a seguir, observa-se que não acontecem alterações significativas nos percentuais das UDIs quando se modifica o parâmetro pé-direito (PD) na mesma orientação. Assim, independente do PD utilizado, o comportamento mostra-se semelhante na mesma orientação. Importante observar, também, a ocorrência de percentuais no intervalo $E>2000$, no céu 7 e no 12, independente do PD, apontando, desse modo, a necessidade de dispositivo de proteção solar para a edificação em determinada faixa do ano.



Gráfico 07 | Comparativo entre percentual das UDIs durante o ano em todas as orientações para os três tipos de céu

Fonte: Autora 
No Gráfico 08, a seguir, encontram-se os dados de lluminância média global, o qual revela o comparativo do comportamento lumínico em resposta à variação do PD para todas as orientações, nos três tipos de céu analisados. Observa-se que na faixa favorável, em destaque, no gráfico 08, correspondente ao intervalo de 500 lux e 2000 lux (suficiente), para os céus 7 (parcialmente nublado) e 12 (claro), com exceção da orientação sul, todas as alturas de pé-direito satisfazem esse intervalo.

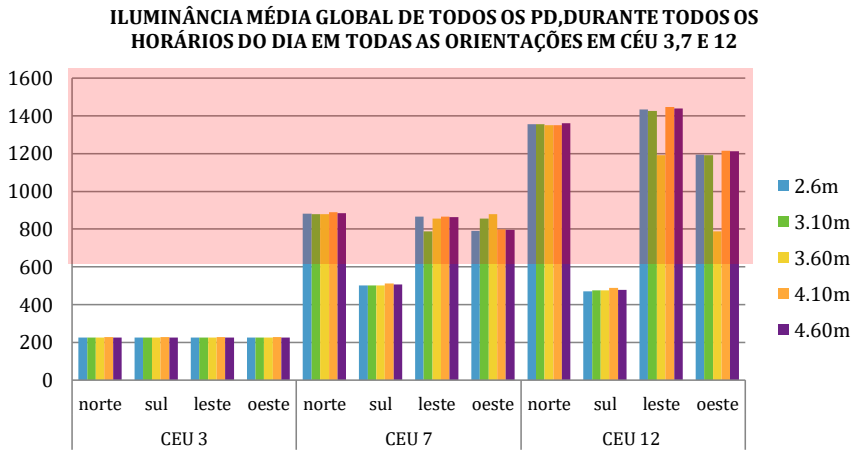

Gráfico 08 | Gráfico comparativo de lluminância média global anual em Céu 3 (encoberto), Céu 7 (parcialmente nublado) e Céu 12 (claro), de acordo o parâmetro PD para as orientações N,S,L e O.

Fonte: Autora 
O Gráfico 09, a seguir, revela o comportamento da Uniformidade da iluminância, no solstício de 21 de março, nos horários compreendidos entre 8h e 17h, nos 3 tipos de céu. Para todos os céus e em todas as orientações, nota-se que, à medida que há o aumento do pé-direito, há uma elevação da uniformidade. Isso ocorre em função da redução da iluminação nos pontos próximos à abertura. Porém, nenhum dos resultados alcançados satisfez a NBR 8995-1. Cabe observar também que, em situações de céu 3, essa iluminância permanece com os menores índices e com baixa variação entre os parâmetros, sendo as situações de céu 12 em que os maiores picos de diferença acontecem.



Gráfico 09 | Gráfico de curvas da Uniformidade da iluminância interna do ambiente em cada parâmetro e orientação, no Solstício de 21 de março 
Uniformidade em 21 de Dezembro no horário entre 8h e 16 horas

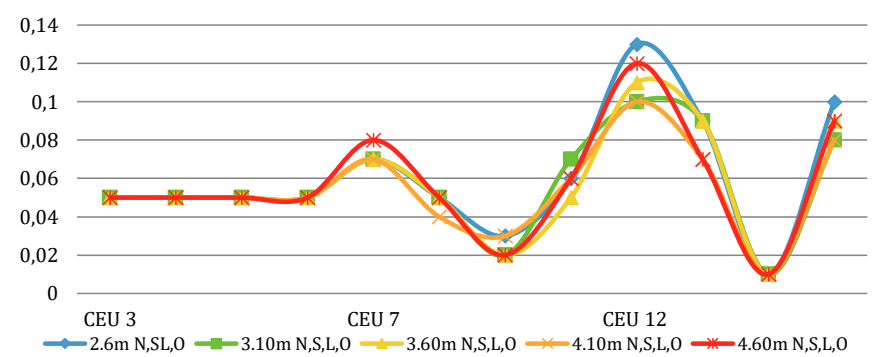

Gráfico 10 | Gráfico de curvas da Uniformidade da iluminância interna do ambiente em cada parâmetro e orientação em Céu 3.7 e 12

Fonte: Autora

\section{Considerações finais}

Destarte, para o panorama analisado, conclui-se que a alteração do parâmetro pé-direito (PD) do ambiente por si só não determina o maior aproveitamento de iluminação natural no interior da edificação. As alterações na iluminação natural, ao se aumentar o pé-direito da edificação, pode ser considerado pouco significativo para ambientes em localidades de características de céu 3 (encoberto), 7 (parcialmente nublado) e 12 (claro). Não foram observados aumentos de iluminância no ambiente interno nos pontos mais profundos do ambiente ao se aumentar o pé-direito. Há, porém, reduções de iluminância nesses pontos mais 
profundos. Contudo, observa-se que há benefícios no aumento do pé-direito do ambiente interno, visto que há uma redução significativa da iluminância próxima das aberturas, o que consequentemente reduzirá os contrastes lumínicos do ambiente interno, com aumentos na uniformidade.

Os resultados indicam também que o parâmetro pé-direito $2,6 \mathrm{~m}$ é favorável à disponibilidade de iluminação natural no ambiente interno, por manter elevada a iluminância do ambiente interno, sendo necessária, porém, a inserção de dispositivos sombreadores para reduzir as altas iluminâncias nos pontos mais próximos das aberturas.

No que tange ao decaimento da iluminância no ambiente interno, em Solstícios e em Equinócios, as curvas Isolux demonstraram que, para todos os céus analisados, em todos os horários, entre 8 h e 17h, há um nível maior de iluminância próximo à janela com pico, nos horários de $10 \mathrm{~h}$ e de $14 \mathrm{~h}$, principalmente nos menores pés-direitos. Evidencia-se, assim, um ambiente com maior desconforto visual, necessitando de estratégias, como dispositivos sombreadores, para controlar o acesso da radiação solar direta, principalmente nos céus 7 (parcialmente nublado) e céu 12 (claro).

Em situações de pés-direitos mais baixos, o desconforto visual torna-se maior. Porém, observa-se também a lineari- 
dade diretamente proporcional: aumenta-se o pé-direito da edificação, de forma que cresce a uniformidade lumínica no ambiente. Isso demonstra que o aumento da variável pé-direito foi favorável ao aumento da uniformidade. Entretanto, a uniformidade obtida ainda se encontra abaixo do indicado pela NBR 8995-1.

Nos intervalos das UDls, observa-se que ao longo do ano há grande demanda por iluminação artificial, em função de percentuais no intervalo suficiente só conseguirem atingir até 34\% das horas do ano para céu 12 (claro), 22\% para céu 7 (parcialmente nublado) e 14\% para céu 3 (encoberto), indicando um ambiente de alto consumo energético nos três céus, para todos os pés-direitos analisados.

Pode-se salientar a necessidade de inserção de dispositivos sombreadores, como exemplo os automatizados, tornando-se uma opção positiva de maior eficiência para o aproveitamento da iluminação natural no ambiente analisado, principalmente os de pés-direitos mais baixos. Isso pode ser justificado por meio da ocorrência, em algumas épocas do ano, sob situações de céu 7 (parcialmente nublado) e céu 12 (claro), de percentuais de iluminação dentro da faixa UDI E>2000, a qual é considerada excessiva.

Por fim, observa-se que o programa Troplux se mostrou eficiente para as análises. Os resultados apontam, porém, 
para a necessidade de simulações em outras configurações urbanas, bem como simulações associando ambientes com pés-direitos variados ao uso da prateleira de luz. Essa associação possivelmente irá contribuir para a não redução da iluminância nos pontos mais profundos do ambiente, garantindo, porém, a redução da alta iluminância nos pontos mais próximos das aberturas, situação observada em todos os pés-direitos testados.

\section{Referências}

ARAÚJO, I. A. L.; CABÚS, R. Influência da luz natural refletida pelo entorno na iluminação de edifícios em cânions urbanos no trópico úmido. In: IX ENCONTRO NACIONAL e V LATINO AMERICANO DE CONFORTO NO AMBIENTE CONSTRUÍDO, 2007, Ouro Preto [MG]. Anais... Ouro Preto [MG]: ANTAC, 2007.

ASSOCIAÇÃO BRASILEIRA DE NORMASTÉCNICAS. NBR 5413: iluminância de interiores. Rio de Janeiro [RJ], 1992.

ASSOCIAÇÃO BRASILEIRA DE NORMAS TÉCNICAS. NBR 15215-4: iluminação natural: verificação experimental das condições de iluminação interna de edificações: método de medição. Rio de Janeiro [RJ], 2005.

ASSIS, E.S; VALADARES, V. M.; SOUZA, R. V. G. Bases para a determinação dos recuos e volumetria dos edifícios, considerando a insolação e iluminação natural, na revisão da lei de uso e ocupação do solo de Belo Horizonte, MG. In: ENCONTRO NACIONAL DE CONFORTO NO AMBIENTE CONSTRUÍDO, 3; ENCONTRO LATINO-AMERICANO DE CONFORTO NO AMBIENTE CONSTRUÍDO, 1, 1995, Gramado.

Anais... Gramado, 1995. 
BRASIL. Portaria $\mathbf{n}^{\circ}$ 372, de 17 de setembro de 2010, que regulamento Técnico da Qualidade para o Nível de Eficiência Energética Edificações Residenciais. Rio de Janeiro, 2010. Disponível em: <http://www.inmetro.gov.br/legislacao/rtac/pdf/RT AC001599.pdf>. Acesso em: 30 jun. 2017.

CABÚS, Ricardo C. TropLux, versão 7.3.2: Cabús, Ricardo, 2006.

GREEN BUILDING COUNCIL BRASIL. [Site institucional]. Disponível em: <http://www.gbcbrasil.org.br/?p=certificacao>. Acesso em: 30 nov. 2016.Preto[MG]: ANTAC, 2007.

HOPKINSON, R. G.; PETHERBRIDGE, P.; LONGMORE, J. lluminação natural. Lisboa: Fundação Calouste Gulbenkian, 1975.

LAMBERTS, R.; DUTRA, L. e PEREIRA, F. Eficiência energética na arquitetura. UFSC/Procel/ Eletrobrás, 1998.

LAMBERTS, R., LOMARDO, L.L.B., AGUIAR, J.C. e THOMÉ, M.R.V. Eficiência Energética em Edificações: Estado da Arte. Procel/ELETROBRÁS, 1996.

LARANJA, A. C. Parâmetros urbanos e a disponibilidade de iluminação natural no ambiente interno. 2010, 285f. Tese (Doutorado em Arquitetura) - Programa de Pós-Graduação em Arquitetura. Universidade Federal do Rio de Janeiro, Faculdade de Arquitetura e Urbanismo, Rio de Janeiro.

LARANJA, A. C.; ALVAREZ, C. E.; MATARANGAS, K. Análise da influência da orientação das aberturas na disponibilidade de iluminação natural no ambiente interno na extensão de sua profundidade. Labor \& Engenho, Campinas [Brasil] v.7, n.1, p.84- 98, 2013. Disponível em: <https://periodicos.sbu.unicamp.br/ojs/index.php/labore/article/view/192/1933> Acesso em: 28 jun. 2017.

LARANJA, A. C.; ALVAREZ, C. E.; CAMPOS, N. P. A influência dos afastamentos laterais das edificações na disponibilidade de iluminação natural no ambiente interno. Labor \& Engenho, Campinas, v. 8, n.4, p. 88-98, 2014.

MORAES, O.; SCARAZZATO, P. S. Iluminação Natural no meio urbano: estudo de caso com o método dos indicadores de altura admissíveis aplicado a Campinas, In: VII Encontro Nacional sobre Conforto no Ambiente Construído, 7. Conferência Latino-Americana sobre 
Conforto e Desempenho Energético de Edificações, 3. 2003, Curitiba. Anais... Curitiba, 2003.

PEREIRA, R. C.; PEREIRA, F. O. R.; CLARO, A. Caracterização da contribuição do entorno na avaliação da iluminação natural em edificações. Ambiente Construído, Porto Alegre, v. 8, n. 4, p. 103-115, out./dez. 2008.

SANTOS ET AL. Impactos Socioambientais Resultados do Processo de Verticalização. In.: VI Congresso Brasileiro de Gestão Ambiental, Porto Alegre/RS, 2015.

VITÓRIA (ES). Código de obras. Lei n. ${ }^{\circ} 4821$, de 30 de dezembro de 1998. Institui o Código de Edificações do Município de Vitória e dá outras providências. Vitória, 1998. p.72.

VITÓRIA (ES). Plano Diretor Urbano. Lei n. 6.705, de 2006. Dispõe sobre o desenvolvimento urbano no Município de Vitória, institui o Plano Diretor Urbano e dá outras providências. Vitória, 2006. p.48. 